\title{
Evolving the service model for child and adolescent mental health services
}

\author{
Barry Wright;, Sophie Roberts, Carol Redmond, Kath Davies, Danielle Varley \\ Lime Trees Child and Family Unit, York, United Kingdom
}

Received: May 13, 2016

Accepted: September 7, $2016 \quad$ Online Published: December 20, 2016

DOI: $10.5430 /$ jha.v6n1p34

URL: http://dx.doi.org/10.5430/jha.v6n1p34

\begin{abstract}
A new model for a community mental health service for children and young people aged 0-18 years is described. This has been formulated after multi-level consultation including extensive user/carer involvement. The proposed model is multidisciplinary and integrated with multiagency provision, with smooth access onto and through care pathways. This model brings voluntary and statutory agencies into an integrated collaboration. It reinforces that social and emotional development and psychological functioning is everybody's business and creates conditions where a child's needs can be addressed on a day-to-day basis rather than through a "clinic-based model".
\end{abstract}

Key Words: Mental health, Children and young people, Community services, Service model

\section{INTRODUCTION}

\subsection{National context}

A recent tender process has prompted a one year period of consultation, workshops and user/carer involvement focussing on young people, parents, professional users, local authorities and other stakeholders. This comes at a time when national task force report "Future in Mind" ${ }^{\text {[1] }}$ proposes new aspirations for child and adolescent mental health services (CAMHS). This is set in the context of the United Kingdom (UK) Children and Families Act ${ }^{[2]}$ and various other policy documents, including The Healthy Child Programme, ${ }^{[3]}$ Getting it Right for Children and Young People: overcoming cultural barriers in the National Health Service (NHS), ${ }^{[4]}$ The Marmot Review, ${ }^{[5]}$ and a report on Achieving Equity and Excellence for Children. ${ }^{[6]}$

Mental health problems represent $28 \%$ of morbidity in the health system and receive $13 \%$ of UK NHS expenditure. ${ }^{[7-9]}$
Within this mental health spending, the funding for CAMHS as a proportion of overall mental health service funding is approximately $6 \%,{ }^{[8]}$ to cover $19 \%$ of the population. CAMHS units have recently been highlighted in the media regarding concerns about inadequate national service provision ${ }^{[9]}$ and investment into services. ${ }^{[8]}$ CAMHS is disproportionately underfunded in comparison to other age ranges. This needs addressing because a large portion of adult mental health problems begin in childhood and adolescence ${ }^{[10,11]}$ with good evidence that prevention is more cost-effective than waiting until mental illness is established. ${ }^{[12]}$ No Health Without Mental Health ${ }^{[13]}$ is a report that sets out a strategy to try and redress the imbalance with low mental health funding. Currently a UK national agenda around Parity of Esteem ${ }^{[8]}$ exists between both physical health care services and mental health services funding. Despite this, surveys of CAMHS providers nationally ${ }^{[14]}$ have reported reductions in funding, rises in demand and increased waiting times.

\footnotetext{
${ }^{*}$ Correspondence: Barry Wright; Email: barry.wright1 @ nhs.net; Address: Lime Trees Child and Family Unit, 31 Shipton Road, York, YO30 5RE, United Kingdom.
} 
In November 2013, the Royal College of Psychiatrists in the UK released "Building and Sustaining Specialist CAMHS to Improve Outcomes for Children and Young People" (CR182). ${ }^{[15]}$ This gives expert guidance on the workforce, capacity and functions of CAMHS in the UK. This report followed considerable consultation amongst users, carers and other stakeholders. It provided indicative figures for workforce capacity and function of specialist CAMHS at all levels. It was written at a time of financial austerity and significant changes in health policy and seeks to put children at the heart of everything that statutory and voluntary child agencies do. In particular, it has paid close attention to guidance for commissioners of CAMH services ${ }^{[16]}$ and the recent work on the payment by results agenda, which is proposed for introduction within CAMHS in the future. ${ }^{[17,18]}$

\subsection{Mental health needs}

National studies suggest that nearly $12 \%$ of 11 to 16 year olds and $8 \%$ of 5 to 10 year olds have a significant mental health problem $^{[19,20]}$ with rates higher for boys $(11.4 \%)$ overall than girls $(7.8 \%)$. In a large meta-analysis ${ }^{[21]}$ the prevalence estimates for low mood and depression were $2.8 \%$ in children under 13 and $5.6 \%$ in 14 to 18 year olds. It would be unthinkable to leave diabetes untreated yet most adolescents with depression do not receive treatment according to National Institute for Health and Care Excellence (NICE) guidelines because the numbers of clinicians is wholly inadequate to deliver treatment to this volume of young people. In 2011 the Office for National Statistics (ONS) reported 159 deaths from intentional self-harm in 10 to 19 year olds in England and Wales (2.35 per hundred thousand). In girls aged 15 to 18 , intentional self-harm occurs at rates of 1,400 per hundred thousand compared to 470 per hundred thousand in boys of this age. ${ }^{[22,23]}$ Given that $53 \%$ young people repeat selfharm after the first episode and $91 \%$ of those committing suicide $(1.4 / 100,000$ per year in under $18 \mathrm{~s})$ have seen their General Practitioner (GP) prior to the event, it is concerning that many have not obtained treatment. ${ }^{[24]}$

It has been suggested that $10 \%$ of children and adolescents have anxiety disorders that interfere with their lives and require treatment. ${ }^{[25]}$ This includes various disorders such as panic disorder, significant social phobia, significant separation anxiety disorder, generalised anxiety disorder and significant phobic disorder. Most of these are treated effectively with psychosocial interventions and require therapists with the skills and time to do this.

The population being served has a population of 300,000 . It is a mix of urban and rural with a range of socio economic groups. It contains small groups of ethnic minorities including a traveller population. In an indicative population

Published by Sciedu Press of 300,000 there are likely to be approximately 580 children with attention deficit hyperactivity disorder (ADHD) between 6-18 years old, 350 3-18-year olds with autism spectrum disorders (ASD) and approximately 115 young people with eating disorders. This is based on ONS data on mental health prevalence in this age group. ${ }^{[19]}$ A small number of young people will have psychotic symptoms requiring treatment. ${ }^{[26}$ Parrott $^{[27]}$ estimated that two million children and young people in England and Wales ( 1 in 6) aged five to 18 will be affected by a parent suffering from a mental illness. Latest estimates are that one tenth of these $(200,000)$ have a significant caring role and are identified as young carers.

Nearly $20 \%$ of school-aged children have special educational needs. ${ }^{[28]}$ Many of these are associated with social, emotional and behavioural difficulties and represent significant mental health risk factors. There are many other risk factors associated with increased mental health problems: ${ }^{[29,30]}$

- Children in care

- Children with physical disabilities

- Children with learning disabilities

- Children with neurological disorders

- Children who are deaf and/or blind

- Children from minority groups (such as black or minority ethnic [BME] families or those from lesbian, gay, bisexual, and transgender [LGBT] families)

- Children from the criminal justice system

- Asylum seekers or refugees

- Children from the travelling community

- Children who have experienced abuse

- Children who are misusing substances

- Children who have a parent with a mental health problem

- Children who are stigmatised

- Children who are LGBT

- Children from low socioeconomic groups or unemployed households

- Children from parents with learning disabilitie

Given these risk factors, commissioners and providers need to address whether specialist CAMHS provide services for only those children with severe and enduring mental illnesses (which is a prevalent adult mental health model), ${ }^{[31]}$ or seek to target those at risk earlier for preventative interventions and also seek to avoid losing young people at transition as a result of large threshold discrepancies. ${ }^{[32]}$ For example, a child who found her father having hanged himself or a child with severe autism may not have a mental "illness" but may need interventions to prevent the development of one.

The recent changes in commissioning arrangements mean 
that services are periodically placed out to tender in the UK. This has some advantages in encouraging service review and refreshing service specifications. However, it also has disadvantages, particularly where commissioners use this to divert funding or prioritise additional savings or if the service specifications are vague or not lined up with local need. Another advantage is that it prompts local services to think clearly about its: priorities, use of resources, models, engagement with the user/carer population, the outcomes it is seeking to achieve and integration with universal services. Recently these rich and varied discussions in our locality have led to the following model. Given that there is limited evidence for the efficacy of any particular service model in CAMHS, we believe it is important to open up a discussion about different types of service models, and also to increase research to be able to compare and test them. Otherwise, the danger is that perceived wisdom and dogma takes hold and drives particular service models at the expense of validated or researched evidence or indeed new ideas that have not been evaluated. A recommendation in Future in Mind ${ }^{[1]}$ suggests dropping the tiered model of service provision originally proposed by the Health Advisory Service document Together We Stand. ${ }^{[33]}$ It makes limited recommendations however about what to replace it with, how to describe levels of service provision or complexity, and reports limited evidence to justify service model changes.

The aim of this paper is to describe the emergence of a proposed service model from a robust consultation and qualitative data collection.

\section{Methods}

\subsection{User/Carer feedback}

Survey feedback took place in two local authorities in our locality. These involved bespoke questionnaires.

A large survey of local young people's opinions ${ }^{[34]}$ from 738 year 10 pupils across $78 \%$ of secondary schools found that $10 \%$ of pupils reported having mental health concerns, $14 \%$ said they had no one to talk to and $21 \%$ felt that they lacked sufficient information about mental health.

In a questionnaire survey from the Schools Health Education Unit in $2015^{[35]}$ with 16,000 local pupil returns, $13 \%$ of females in key stage 3 and 4 said that they had harmed themselves at least once. Of secondary school pupils $28 \%$ boys and $17 \%$ girls scored "high" (28-35) on the short Warwick Edinburgh Mental well-being (SWEMWB) scale. It was also reported that $70 \%$ of secondary school pupils were worrying about at least one problem "a lot" or "quite a lot", with the most worries being exams, appearance, family problems and health problems. Further, $11 \%$ of males and $24 \%$ of females reported receiving unpleasant or hurtful comments online.

This data has been fed back through a series of meetings with local providers to discuss models. We have conceptualised providers in a broad sense including specialised CAMHS, local authority provision (e.g. youth services, Connexions, schools, specialist teacher provision, educational psychology services), health services (e.g. paediatrics, child development centre, school nurses) and voluntary agency provision. Two local "Discover" events were organised by the CCG which involved users, carers and other stakeholders. ${ }^{[35]}$

A summary of feedback to scope mental health services that come from this consultation work included more emphasis on prevention, reducing stigma in access to services (including access in schools and more inventive ways to make mental health well-being more mainstream) more access to early intervention, and improved training for teachers and youth workers. There was also a request for more information and integration of voluntary service offerings, and a desire for better joining up of services (e.g. between schools, CAMHS, Youth workers, voluntary agencies etc.). This information was fed into the project group.

\subsection{Qualitative data collection}

Whilst patient or clinician-related outcome measures or experience of service measures describe existing service provision and models, they do not give good information about alternative models. Qualitative data can yield helpful feedback and innovative ideas about future directions.

In our recent service review we included focus groups with the local youth council, which has taken a particular interest in child and adolescent mental health, with representatives from 12 different secondary schools in our locality. In addition, young carers from a local young carers forum, and children and adolescents with mental health problems within the current service (both in focus groups and in questionnairebased feedback) were included. We also carried out animated film-making projects funded by various charitable monies where groups of young people gave opinions about particular services, and other aspects of care based around their own area of interest including deaf young people, young people with diabetes, Asperger syndrome, ADHD, anorexia nervosa, young people who self-harm and parents of children with ASD.

A number of meetings were held: two meetings involving numerous local voluntary agencies that have some aspect of provision for children and young people with mental health problems, meetings with three different local authorities and their children teams, a meeting with pastoral care leads and head teachers from local schools, and meetings with the local 
Clinical Commissioning Group (CCG). These focus groups and meetings occurred on two or more occasions for some of these groups.

This information was thematically analysed and summarised and fed into a project group made up of senior clinicians, managers, service users and a well-known international company providing advisory and project management services. This group wrote the model as described here for presentation to commissioners, where it achieved a rating of 4 out of 5 for quality.

\section{Results}

\subsection{A proposed model}

Most stakeholders favour a system that moves away from a highly referral-based system (with referral status only given to some professionals) into one where any child flagged up as having need can access services at a level commensurate with their need. Parents or teachers can flag up concerns and any professional can make a referral (e.g. teachers, health visitors, paediatricians etc.). The system also moves away from a belief that a child needs to be "fixed" and therefore needs to go to a particular service only to be returned when that has occurred. Instead, it opts for a model where any child with emotional, psychological, mental health or social difficulties can access provision across a range of environments and that these are provided closest to the child's environment (e.g. in schools, the community and local clinics). A "team around a child" ${ }^{[36]}$ approach sometimes cited in work with children who have complex needs or early intervention work, shares responsibility for improving a child's outcomes and most stakeholders are positive about working together for a child or a family if they are adequately resourced and supported. The care plan therefore does not reside in one agency, but is shared. For example, a child receiving cognitive behaviour therapy (CBT) and medication for severe depression, can simultaneously, see key individuals within school and at home who are supporting aspects of their recovery as part of a supportive team around that child. Whilst that has been an aspiration in previous described service models, it has rarely been enacted. This York model seeks to explicitly address that.

The model is presented in Figure 1 and described further below. In summary a child or a young person may be identified in school as having a mental health problem (for example anxiety). That school cluster, which includes a CAMHS band 5 worker may suggest a care plan put together with child, family and cluster team member that is carried through within school. If the problem deteriorates the local PMHW who links to that cluster team may assess the child and take them up through specialist services (e.g. seeing a psycholo- gist for CBT or a psychiatrist for medication) or indeed for admission. Voluntary agency provision is also available as part of a holistic care plan.

The innovative features of this model include that fact that it allows for the needs and choices of service users ${ }^{[37]}$ and that the emotional, psychological and mental health of children and young people is everybody's business. Care pathways should involve multidisciplinary, multiagency working. Children and young people should be able to move up and down this care pathway depending on need without need for "referral" in or out of unconnected services. Services should be integrated and not fragmented. There should not be unhelpful boundaries between services. Services should be accessible and should be non-stigmatising and empowering. Services should also be evidence-based. The model therefore includes a single point of access that acknowledges the need for an easy access route into services but with the York refinement of centrally accessible locality-based assessments (CALBA). These assessments are provided by locality based mental health professionals who have ongoing working relationships with clusters of schools. The single point of access can link directly to the school based clusters or specialist services. Further, it involves a partnership approach to working with families, ${ }^{[38]}$ measures outcomes to monitor progress, ${ }^{[39]}$ and also promotes the importance of measuring outcomes that are meaningful to service users, and not wholly driven by contracting targets.

Some of the key features of this model include accessibility, child and family focused ethos and culture, and partnerships. The team would be involved in research and audit and this would be set in a multiagency context to implement interventions (such as delivery of Social Stories ${ }^{\mathrm{TM}}$ interventions for autism, and ongoing innovative evidence based research). The model utilises strong partnerships with local young people, local and national voluntary agencies, Local Authorities and acute health service Trusts (all of whom work with children). There would also be service involvement in local multiagency planning groups (e.g. CAMHS partnership groups and Children's Trusts), including planning and delivering integrated services, and the regular involvement of users and carers in the running, development and evaluation of services. Further, there would be use of routine and regular outcome measurement to monitor progress in all consenting service users and their families. There would be implementation of a programme of on-going audit, evaluation and improvement work based on national and local priorities. Additionally, the model implements clear auditable waiting time limits and innovative use of information and technology as requested by young people. A no tolerance attitude to stigma associated with mental health services is part of the ethos. 


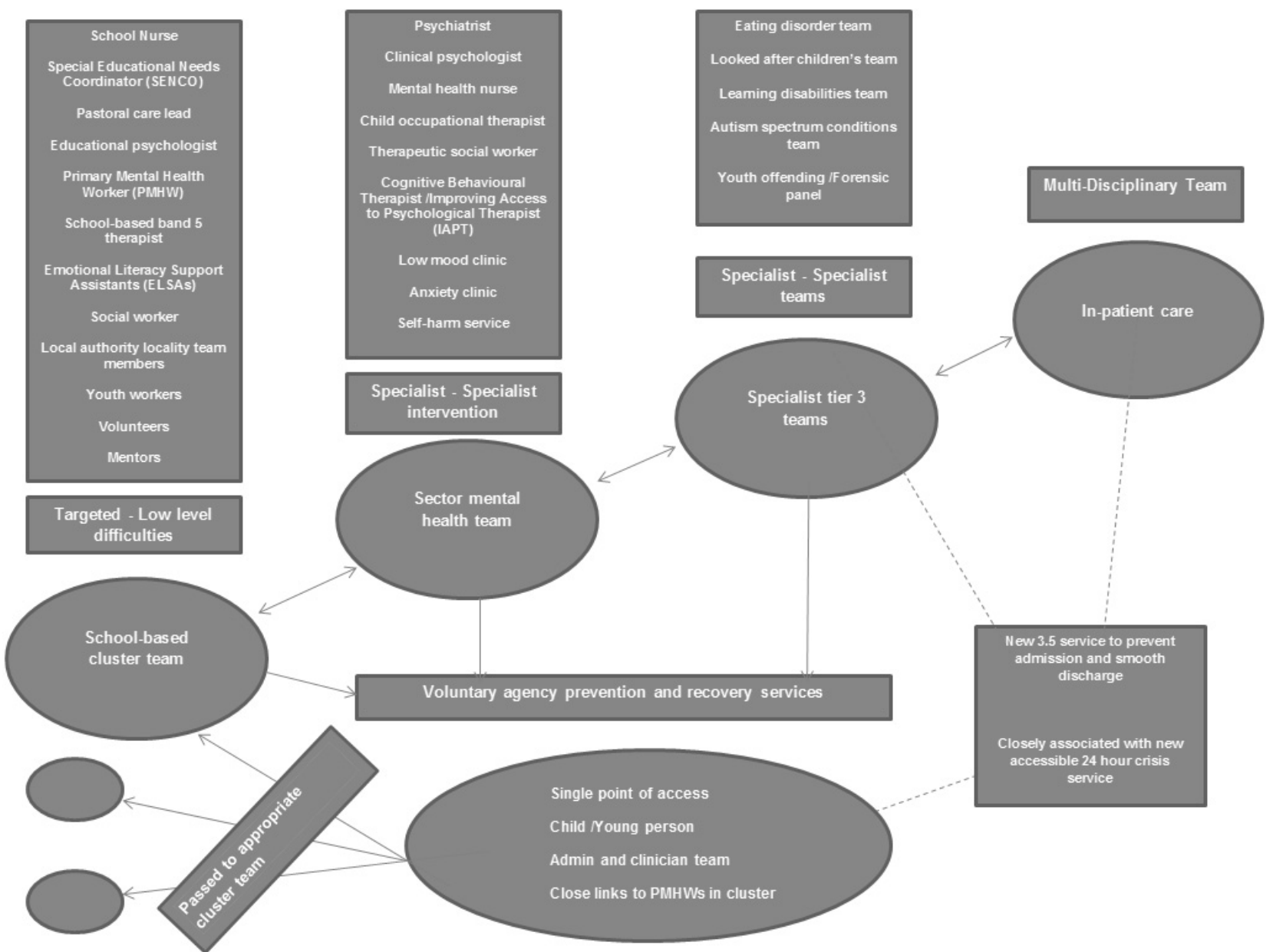

Figure 1. CAMHS Service Model

\subsection{Regulatory frameworks}

Services will work within established legislation and guidance notably: The Mental Health Act 1983 (updated 2007) and its Code of Practice, The Mental Capacity Act 2005, The Children and Families Act 2014, The National Service Framework 2004, The Care Act 2014, The Equalities Act 2010, Working Together to Safeguard Children 2013 and locally agreed multiagency guidance, and the Human Medicines Regulations 2012.

\subsection{What does this look like for children and young people?}

Figure 1 described the model schematically.

\subsubsection{Day-to-day provision}

The day-to-day provision of the service model will include health promotion and providing support to the socioemotional and psychological development of all children and young people. Nurturing and support will be provided by a large range of professionals, family members, and community-based relationships. Professionals involved will include: health visitors, teachers, pastoral care staff, school nurses, GPs, paediatricians, early intervention workers, youth workers, family support workers, social workers, Connexions workers, drop-in centre workers, dieticians, speech and language therapists and various other professionals. Third sector professionals would also be part of the teams.

To allow the day-to-day provision of this proposed service model to run effectively, we recommend three aspects. Firstly, the aforementioned professionals would provide this support on a day-to-day routine basis, with training as appropriate. Secondly, this would be organised in a cluster-based model where the above professionals network around secondary schools (and feeder primary schools) and discuss children with mental health needs, within those schools. They have a direct vested interest in the well-being of those children. This group would meet 2-4 times a term and be established and commissioned with part funding from schools (pupil premium funding), local authorities and the CCG. These cluster meetings would support existing staff and reduce anxiety by providing consultation and networking. 
Those receiving this support would include young people with sexual health problems being seen by school nurses, young people with school-based anxiety difficulties, bullying and relationship issues seen by pastoral care leads, learning problems by educational psychologists and relationship problems by emotional literacy support assistants (ELSAs: teaching assistants with additional training). This network would have within it a school-based practitioner from CAMHS who will provide supervision, some direct work, support for establishing in-school group work, advice and consultation and link up the care pathway through involvement in triage assessments for more complex problems. The cluster team provides cohesion, monitor patterns, arranges training and gives a voice to psychological issues in schools. The third aspect is the development of a network of voluntary agencies providing local services overseen by a local group of representatives from CAMHS and commissioners in partnership with voluntary agencies and user/carer groups. Standards would be set and limited funding made available to support local information, networking, standard setting and project working. This funding would come from local commissioners and charitable fundraising. A voluntary agency network is being established locally to provide activities for young people, prevention for vulnerable or isolated young people and a step down service for those recovering. This includes music groups, arts therapies, creative activities (e.g. art, drama, sports clubs, daily living skills groups) and a range of other groups and activities. Some of these are specific, such as a local group for young people with Asperger syndrome.

\subsubsection{Accessible therapies}

Where children or young people require more than this the cluster team network would access other parts of the care pathway through the Primary Mental Health Worker (PMHW) employed by CAMHS. In this accessible day-today support and low level therapies are provided by professionals such as PMHWs, educational psychologists, paediatric nurses, counsellors, educational psychologists and psychotherapists, mental health nurses, learning disability therapists and a range of other professionals. These are best organised around localities (e.g. in community mental health teams, sectors or patches). These would include therapies such as CBT, interpersonal therapy, parenting work and group work. Therapies would be NICE guideline compliant with mechanisms for assessing new guidelines and liaising between providers/stakeholders and commissioners when new treatments are recommended.

\subsubsection{Specialist services, teams and provision}

Sometimes, children and young people may need more specialist help and this would be organised with the necessary expertise. Some of this would need to be in community clinic-based settings to manage workload, but could also be organised in schools where practicable. The model design was heavily influenced by the risk factor data collected locally. This would often involve multiagency professionals working together to provide services such as an ASD team (with agreed established partnerships with child mental health professionals, paediatricians, educational psychologists, speech and language therapists and specialist education autism workers). In York this is organised around a multiagency ASD forum. ${ }^{[40]}$ In addition, an ADHD clinic (with agreed established partnerships with child mental health professionals, paediatricians, educational psychologists) a low mood, depression and anxiety service (linking child mental health professionals with cluster-based support teams based around schools), and a self-harm service for prompt assessment and follow-up. A home treatment team could support young people intensively within the community to prevent admission, reduce length of stay for those requiring admission and establish smooth transition.

Other specialist services that may need to be involved include family therapy services (with multiagency staff including mental health, educational and social service professionals), learning disability services (with agreed established partnerships between child mental health professionals, health and disability social workers, paediatricians and the Child Development Centre multidisciplinary team). They would work alongside an established team to support children with learning disability and complex needs to prevent out of area placement and maintain young people in their own homes (with agreed established partnerships between child mental health professionals and the local authority health and disability team), and a looked after children's team (with agreed established partnerships with local authority social work and adoption and fostering teams and children's residential facilities). Further services include: psychosis services (with agreed established partnerships between child mental health professionals and the early intervention service for psychosis serving young people from 14 upwards), forensic panels and related services (with agreed established partnerships between child mental health professionals, social services, forensic services); paediatric liaison services (with agreed established weekly meetings and partnerships between child mental health professionals and paediatric services); and eating disorders services (with agreed established partnerships with child mental health professionals, child health services, dieticians). As seen all these specialist services require partnership working.

\subsubsection{Residential provision}

Residential provision refers to regional or superregional services. This includes residential facilities for children with 
eating disorders, psychosis and severe mental health problems, services for children with learning disability and mental health problems, and provision for deaf children with mental health problems (National Deaf CAMHS). ${ }^{[41]}$

\subsubsection{Urgent or emergency provision}

A range of systems placed within CAMHS would allow prompt access to anywhere on the care pathway through a series of fast-track systems with rapid response depending on need. There would be regular school-based cluster cross agency meetings to support day-to-day provision and the professionals in supportive roles (2-4 per term) and Community Mental Health team meetings weekly within locality sectors. Urgent services implemented would include an urgent 24/7 psychiatric emergency system, a daily duty clinician system for urgent work involving higher levels of concern (e.g. risk of harm to self or others or risk of school or home breakdown) and a crisis and home treatment service based in the community and working closely with tier 4 residential provision (24/7). This crisis service would be CAMHS specific during the day but would co-work with adult crisis services during the night. This system allows children, young people and families to be readily directed to the most appropriate professional within services promptly.

\subsection{Population covered}

The service will work with children and young people registered with a CCG boundary GP aged between $0-18\left(18^{\text {th }}\right.$ birthday). There would be a clear transitions policy with adult mental health services and learning disability adult services that allows flexibility in continuing to see young people beyond their $18^{\text {th }}$ birthday or jointly work between services.

Specialist CAMHS will see any children with a suspected mental health disorder including:

- Depression or bipolar disorder

- Mania

- Anxiety disorders (such as panic disorder, serious phobic anxiety, generalised anxiety, severe separation anxiety disorder of childhood, social anxiety disorder of childhood, Obsessive Compulsive Disorders and severe adjustment reactions)

- Eating disorders (i.e. anorexia nervosa or bulimia nervosa)

- Psychotic symptoms regardless of diagnosis (but including schizophrenia, drug-induced psychosis and temporal lobe epilepsy) [these children and young people are seen jointly with the Early Intervention Service - see adult service specification]

- ADHD or Hyperkinetic disorder

- Children who have experienced trauma across a range of settings and ages
- Mental ill health in the context of substance misuse

- Any mental health disorder in conjunction with a learning disability

- Somatisation disorders

- Self-harm or suicidal ideation with a suspected mental health disorder

- Moderate to severe family problems likely to impact upon future mental health

- Pathological grief or severe or prolonged grief reactions

- Attachment disorders

- Any of the above alongside a conduct disorder

- Any child at high risk of developing a mental health disorder

The cluster teams working into schools would see children with milder problems such as bereavement, conduct disorder, oppositional defiant disorder, mild anxiety disorders such as phobias and social anxiety. Cluster teams would also support children or young people returning to the community for example after depressive illness.

\section{Transition team}

The transition for young people between child and adolescent adult services would be supported by specialist teams and adult services such as the early intervention service and learning disability service. A virtual transitions team would identify professionals from both services who would regularly meet and work together to provide services for young people aged between 14-25 years.

\section{DiscuSSION}

This paper has discussed the emergence of a proposed service model for children and adolescent mental health care from extensive discussions with patients, carers, and local agency consultation. The innovative elements of this model are that it is accessible and has smooth care pathways. A single point of referral access is utilised whilst initial assessment is locality-based (rather than clinic based) with multidisciplinary, multiagency triage systems. The service is integrated across levels of need avoiding the need for multiple inter-team referrals. Each level of service is joined up to adjacent elements of the care pathway with professionals who know each other well. This means that children and young people do not bounce around in the gaps between services because each child has a keyworker and a care plan involving local professionals and parents/carers, and specialist workers where necessary. In this way there are integrated care pathways/services, training, supervision, support and management, with clear care pathways integrated across statutory and voluntary services for all mental health 
disorders and those at risk. A voluntary agency network of services provides a back-drop of activity based support for young people with mental health problems. Lastly, the model enables the establishment of cluster teams around networks of schools to increase universal service professionals including the training and deployment of 190 ELSAs across York schools funded by schools. This innovative development means that schools are at the heart of mental health provision in a way that was never previously possible.

The model also addresses some previous transition limitations ${ }^{[32]}$ by creating a virtual team (14-25 years of age). This links both teams together in function, purpose and policy and also prevents the creation of two seams at age 14 and 25 to replace the current one at age 18 . One of the barriers identified in transition relates to different conceptual views and training related to mental health problems between CAMHS and adult mental health servicer. Whilst the model described here does not make fundamental inroads into these large differences, it does place workers together to learn from each other and influence practice, and begin the shared planning recommended by other authors. ${ }^{[42]}$ This does not address the large conceptual differences in provision of preventive services and thresholds for access (e.g. people with neurodevelopmental difficulties ${ }^{[43]}$, which requires more of a national policy discussion to effect meaningful change.

The challenge of this model is that is requires a shared vision between providers such as health providers, local authorities, voluntary agencies, and schools alongside a willingness of commissioners to invest in this. This can sometimes be difficult to align, particularly if funding is limited. However, the process of model development in any locality brings all these organizations together in dialogue, which in our experience is in itself a powerful process that can lead to the benefit of local children.

Other large challenges of this model are to maintain its integration and networking in a financial climate where tight budgets inevitably lead to pressures to reduce services, and/or for services (e.g. the NHS or local authority) to retrench to perceived core business, which mitigates against integration and multiagency working. Commissioners ultimately choose which models to fund and this can be for a variety of reasons including financial, political or conceptual. This requires us to have wise and knowledgeable commissioners prepared to stand up for children, young people and their families, since these decisions can make substantial changes to service provision.

\section{Conclusions}

One of the reasons that we are keen to publish this proposed model is that in general there is very little information or research about service models in child mental health services and how they perform in comparison with each other. We hope that this paper will provoke discussion and thought about how services are shaped and planned, and will hopefully lead to more research and a better evidence base. We commend this model to commissioners. It is borne from extensive stakeholder and user/carer feedback and experience, and meets all the Future in Mind ${ }^{[1]}$ requirements.

\section{CONFLicts OF InTEREST Disclosure} None.

\section{REFERENCES}

[1] Department of Health. Future in Mind: Promoting, protecting and improving our children and young people's mental health and wellbeing. London: Department of Health; 2015.

[2] Department for Education. Mental Health and Behaviour in Schools. London: Department for Education; 2014.

[3] Department of Health. The Healthy Child Programme. London: Department of Health; 2009.

[4] Department of Health. Getting it Right for Children and Young People: overcoming cultural barriers in the NHS. London: Department of Health; 2010a.

[5] Marmot Review. Fair Society Healthy Lives. London: UCL; 2009.

[6] Department of Health. Achieving Equity and Excellence for Children. London: Department of Health; 2010b.

[7] Royal College of Psychiatrists. Bridging the Gap: The Financial Case for Reinvesting in Mental Health. London: Royal College of Psychiatrists; 2013. The Stationary Office. The Care Act 2014. London: The Stationary Office; 2014.

Published by Sciedu Press
[8] House of Lords. Parity of esteem for Mental and Physical Health. London: House of Lords; 2013.

[9] House of Commons. Third Report from the Health Committee, Children's and Adolescents' Mental Health Services and CAMHS (HC 342) and the Government Response (HC 1036). London: House of Commons; 2015.

[10] Costello EJ, Egger H, Angold A. 10-year research update review: the epidemiology of child and adolescent psychiatric disorders: Methods and Public Health Burden. Journal of the American Academy of Child and Adolescent Psychiatry. 2005; 44: 972-86. PMid: 16175102. https://doi.org/10.1097/01.chi.0000172552.41596.6f

[11] Kim-Cohen J, Caspi A, Moffitt TE, et al. Prior juvenile diagnoses in adults with mental disorder: developmental follow-back of a prospective-longitudinal cohort. Archives of General Psychiatry. 2003; 60: 709-17. PMid: 12860775. https://doi.org/10.1001/ archpsyc.60.7.709

[12] O'Connell ME, Boat T, Warner KE. Preventing Mental Emotional and Behavioural Disorders in Young People: Progress and Possibilities. Washington DC: National Academies Press; 2009. 
[13] Department of Health. No health Without Mental Health: a crossgovernment mental health strategy for people of all ages. London: Department of Health; 2011.

[14] House of Commons. Children's and Adolescents Mental Health and CAMHS. London: House of Commons; 2014

[15] Royal College of Psychiatrists. Building and Sustaining Specialist CAMHS to Improve Outcomes for Children and Young People (CR182). London: Royal College of Psychiatrists; 2013.

[16] Joint Commissioning Panel for Mental Health. Guidance from Commissioners of Mental Health Services for Young People Making the Transition from Child and Adolescent to Adult Mental Health Services. Volume 2: Practical Mental Health Commissioning. London: Royal College of Psychiatrists; 2012.

[17] Royal College of Psychiatrists. Consultant Document: CAHMS Payment by Results (PBR). London: Royal College of Psychiatrists; 2012.

[18] Wolpert M, Vostanis P, Young S, et al. Child and Adolescent Mental Health Services Payment System Project: Final Report. London: CAMHS Press, London; 2015.

[19] Green H, McGinnity A, Meltzer H, et al. Mental Health of Children and Young People in Great Britain. Newport: Office for National Statistics; 2004.

[20] Office for National Statistics. Annual Mid-year Population Estimates for England and Wales 2012. London: Office for National Statistics; 2013.

[21] Costello EJ, Erkanli A, Angold A. Is there an epidemic of child and adolescent depression. Journal of Child Psychology and Psychiatry. 2006; 47: 1263-71.

[22] Hawton K, Saunders KEA, O' Connor R. Self-harm and suicide in adolescents. The Lancet. 2012a; 379: 2373-2382. https://doi . or g/10.1016/S0140-6736(12)60322-5

[23] Hawton K, Bergen H, Kapur N, et al. Repetition of self-harm and suicide following self-harm in children and adolescents: findings from multicentre study of self-harm in England. Journal of Child Psychology and Psychiatry. 2012b; 53: 1212-1219. PMid: 22537181.

[24] Windfur K, Kapur N. Suicide and Mental Illness: A Clinical Review of 15 Years Findings from the UK National Confidential Inquiry into Suicide. British Medical Bulletin. 2011; 100: 101-121. PMid: 21948337. https://doi.org/10.1093/bmb/ldr042

[25] Silverman WK, Field AP. Anxiety Disorders in Children and Adolescents. Cambridge: Cambridge University Press; 2011. https: //doi.org/10.1017/CB09780511994920

[26] Kelleher I, Connor D, Clarke MC, et al. Prevalence of psychotic symptoms in childhood and adolescence: a systematic review and meta-analysis of population-based studies. Psychological medicine. 2012; 42: 1857-1863. PMid: 22225730. https ://doi.org/10.1 017/S0033291711002960

[27] Parrot L, Jacobs G, Roberts D. SCIE Research Briefing at 23: Stress and Resilience Factors in Parents with Mental Health Problems and Their Children. London: SCIE; 2008.

[28] Council for Disabled Children. Using the Children and Families Act to improve outcome for children and young people with SEN and disability. London: Council for Disabled Children; 2013.
[29] Huffman LC. Risk Factors for Academic and Behavioral Problems at the Beginning of School. Dissertation. Stanford University. 2000.

[30] Rutter M, Bishop D, Pine D, et al. Rutter's Child and Adolescent Psychiatry. Fifth Edition. Part III: Influences on Psychopathology. Oxford, UK: Blackwell Publishing; 2008. 339-521 p. https : //doi.org/10.1002/9781444300895

[31] Kazdin AE, Rabbitt SM. Novel Models for Delivering Mental Health Services and Reducing the Burdens of Mental Illness. Clinical Psychological Science. 2013; 1: 170-191. https ://doi.org/10.117 $7 / 2167702612463566$

[32] Singh SP. Transition of Care from Child to Adult Mental Health Services: the Great Divide. Current Opinion in Psychiatry. 2009; 22 : 386-390. PMid: 19417667. https://doi.org/10.1097/YCO.0b 013e32832c9221

[33] Health Advisory Service. Together We Stand: Thematic Review of the Commissioning, Role and Management of Child and Adolescent Mental Health Services. London: The Stationery Office; 1995.

[34] Yor-Ok Review of Children and Young People's voice - 2015. Available from: www.yor-ok.org.uk/downloads/involvment/ reviewofvoice2015.pdf

[35] Schools Health Education Unit Growing up in North Yorkshire. A summary of the growing up in North Yorkshire Survey. 2014.

[36] Limbrick P. Early support for children with complex needs and their families: team around the child and the multiagency key-worker. Worcester: Interconnections; 2004.

[37] Wolpert M, Harris R, Jones M, et al. Thrive - The AFC-Tavistock Model for CAMHS. London: Anna Freud Centre and the Tavistock and Portman NHS Foundation Trust; 2014.

[38] Mental Health Foundation with the National CAMHS Support Service. Evaluation of the Choice and Partnership Approach in Child and Adolescent Mental Health Services in England. London: The Mental Health Foundation; 2009.

[39] Children and Young People's Outcomes Strategy. Report of the Children and Young People's Health Outcomes Forum. London: Department of Health; 2012.

[40] Wright B, Williams C, Smith R, et al. An Autism Spectrum Disorders Forum. 2016.

[41] Wright B, Walker R, Holwell A, et al. A new dedicated mental health service for deaf children and adolescents. Advancement of Mental Health. 2013; 11(1): 2141-2163.

[42] Pottick KJ, Bilder S, Vander SA, et al. US patterns of mental health service utilization for transition-age youth and young adults. The Journal of Behavioral Health Services \& Research. 2008; 35(4): 37389. PMid: 18026842. https://doi.org/10.1007/s11414-007 $-9080-4$

[43] Singh SP, Paul M, Ford T, et al. Transitions of care from child and adolescent mental health services to adult mental health services (TRACK study): a study of protocols in Greater London. BMC Health Services Research. 2008; 8(1): 1-7. PMid: 18573214. https://doi.org/10.1186/1472-6963-8-135 